\title{
Knowledge and attitudes about the 'green car' concept among officers of a bank in Colombo district.
}

\author{
E N O B Silva , L A N Silva ", L H P M Silva ${ }^{1}$, S M J Arul ${ }^{1}$, Gominda Ponnamperuma ${ }^{2}$ \\ 2 \\ Department of Medical Education, University of Colombo, Sri Lanka
}

Article Information
Total number of
Words 2835
Tables 03
Authors have no conflicts of
interest to declare
Keywords: green cars, green technology,
environmental sustainability, sustainable
development goals, eco-friendly

Date of submission: 14.02 .2017

Date of acceptance: 02.10 .2017

DOI:

http://doi.org/10.4038/cjms.v54i2.4928

\section{Author responsible \\ for correspondence: \\ E N O B Silva, \\ 1/20 Linton ground, Peralanda, \\ Ragama. Mobile: 0776866599 Email; \\ bhagyasilva1993@gmail.com}

http://orcid.org/0000-0003-4143-6129

\begin{abstract}
Introduction

„Green cars" have a history which runs back to the origin of green technology itself. They play a main role in environmental sustainability, in achievement of sustainable development goals. Although studies have been conducted on assessing the consumer knowledge and attitudes on 'green cars', studies investigating the association between these components are lacking. The main objective of our study was to describe and compare the factors associated with knowledge and attitudes about the ,green car"e concept among officers of a bank in Colombo district.

Method

This is a descriptive cross-sectional study. A two-stage sampling process, involving non-systematic sampling to select venue and stratified sampling to select subjects within the venue was used to select a sample of 300 . Using a selfadministered questionnaire, knowledge and attitudes were assessed. Knowledge against socio-demographic factors was investigated using independent sample ttest. Attitudes against socio-demographic factors were investigated using Chisquare test.
\end{abstract}

\begin{abstract}
Results
Response rate was $95.6 \%$. Majority (54\%) had a high level of knowledge, but knowledge on 'green car' identification and electric car recharging was poor. Most important factor considered when buying a vehicle was cost, while most important factor discouraging buying an electric car was recharging issues. Although most were found to have eco-friendly attitudes, bank officers with a higher level of knowledge were more pro-environmental. Majority (55\%) of them were willing to buy a 'green car' as their next vehicle.
\end{abstract}

\section{Conclusion}

Awareness and knowledge of bank officers on the 'green car' concept was at a satisfactory level. A higher level of knowledge was associated with more ecofriendly attitudes.

\section{Introduction}

The ,go green ce concept is a universally adopted strategy to accomplish goals of environmental sustainability, which is one of the three pillars of sustainability. Sustainable development is defined as "development that meets the needs of the present without compromising the ability of future generations to meet their own needs" [1].
Transport is energy intensive. In the long run, the technology and energy used to provide this service should be sustainable. This implies that the energy should be derived from renewable sources, and the entire energy chain, ,well to wheelee, should not emit harmful emissions to the environment [2]. 
The ,green car' concept is in fact a subdivision of „go green' concept contributing to environmental sustainability, directly by contributing to sustainable waste disposal and indirectly by encouraging the balance between depletion and regeneration of nonrenewable resources. "As part of their contribution to sustainable transport, these vehicles reduce air pollution and greenhouse gas emissions, and contribute to energy independence by reducing oil imports" [3].

A 'green car' is defined as a road motor vehicle that produces less harmful impact on the environment than comparable conventional internal combustion engine vehicles running on gasoline or diesel, or one that uses certain alternative fuels or a conventional car fine-tuned to the recommended vehicle emission standards [3]. Therefore, the term 'green cars' covers several vehicle categories including conventional cars meeting recommended vehicle emission standards, hybrid electric vehicles, plug-in hybrid electric vehicles etc.

Emission from on-road motor vehicles is one of the main air pollutants in Sri Lanka. Ever increasing use of vehicles in transport sector without proper monitoring, controlling and regulation of emissions, together with the lack of standards and the national interest, has resulted in deterioration in air quality in the main cities, especially in Colombo. This has caused adverse health conditions and poor quality of life [4]. However, Nationwide, electric vehicles charged from the electricity grid produce lower global warming emissions than the average compact gasoline-powered vehicle (with a fuel economy of 27 miles per gallon) even when the electricity is produced primarily from coal in regions with the "dirtiest electricity grids" [5].

Studies assessing the association between knowledge and attitudes with regard to cardiovascular diseases among women [6] and relationship between air pollution and respiratory diseases [7] had shown that there was a significant relationship between high level of knowledge and healthy lifestyles. Similarly, improving awareness on the green car concept could act as an adjunct to encourage pro-environmental behaviour. [8]. This study was done to assess the knowledge and attitudes on green car concept, factors affecting those two parameters and their association with each other, as an attempt to identify challenges for green car usage in Sri Lanka.

\section{Methods}

Our study was conducted at Bank of Ceylon Head Office which has a large number of bankers from all over the country; a significant proportion owned a vehicle.

Bank officers serving for more than one year were included. Those officers involved in marketing of green cars as an additional method of income were excluded.

It was a descriptive cross-sectional study. Standard sample size calculation formula was used at a confidence interval of $95 \%$. With an allowance of 12 for defaulters and non-responders a sample of 300 was selected.

Sampling was done according to a two-stage sampling process. First stage was selecting Bank of Ceylon Head Office through non-systematic sampling. Second stage, was carried out according to stratified sampling method. Bank officers were stratified according to the floor they were working in. Then a random sample of bank officers were selected from each floor.

Study instrument was a self-administered questionnaire which comprised the study variables: general information on socio-demographic factors such as age, sex, residence, marital status, type of vehicle owned, frequency of vehicle usage, etc.; knowledge on the green car concept; and attitudes on the green car concept. Items on knowledge and attitudes were generated using questionnaires used in similar studies as models, they were modified to match the Sri Lankan context while new items were created in areas which we thought would need more assessment.

Statistical analysis was performed using SPSS: version 20 . Knowledge was assessed by totaling the ratings for individual items, whereas attitudes were assessed item-by-item. Knowledge against sociodemographic factors was assessed using independent sample t-test, at a significance level of $\mathrm{p}<0.05$. Attitudes against socio-demographic factors were assessed using Chi-square test, at a significance level of $p<0.05$. Ethical clearance was obtained from Ethics Review Committee of Faculty of Medicine, University of Colombo.

\section{Results}

Respondent rate was $95.6 \%$. Majority were in the age group of $32-38$ years and male to female ratio was almost 1:1. Most were married (74.6\%) and degree holders $(58.5 \%)$.

Majority $(67.1 \%)$ of them owned a personal vehicle, but only $15.4 \%$ of them owned a car in 'green car' category; $90.7 \%$ of which were hybrid cars.

Most (68\%) of bankers were aware of the green car 
concept. On assessment of the knowledge on this, only $54 \%$ fell into the category of high knowledge. Nissan Leaf was correctly identified as a 'green car' by most $(68.3 \%)$ while Toyota Allion was the car most misidentified as a 'green car' by most $(96.2 \%)$. The questions answered correctly and incorrectly by majority in order were ,sources of energy utilized by hybrid cars' $(87.5 \%)$ and 'time taken to fully recharge an electric vehicle' (67.9\%).

In decreasing order of frequency, features considered when buying a vehicle were cost, safety, comfort and eco-friendliness. Similarly the factors discouraging buying 'green cars' were the recharging issue, cost, limited choice, lack of knowledge and safety. Majority $(84.5 \%)$ agreed that government should provide incentives to buy 'green cars', $88 \%$ believed that an individual can contribute to reduction in air pollution by way of buying 'green cars'. Although $91.8 \%$ stated that they were willing to contribute to a greener environment by purchasing a green car, $49.2 \%$ of them stated that they were unable to afford such a vehicle.

Majority (74\%) agreed that the demand for fossil fuel could be decreased by using 'green cars' and $43.5 \%$ disagreed 'environmental pollution during manufacture of 'green cars' is greater than conventional tail pipe emissions". When respondents were asked to state the likelihood of buying a 'green car', $61.3 \%$ responded affirmatively. However, majority were uncertain about 'green cars' replacing conventional cars over time.

Significant association was found between bank officers who were males, married and with a degree with a higher level of knowledge and those who were not aware of the 'green car' concept with a lower level of knowledge. Age, vehicle ownership and type of vehicle owned were not significantly associated with the level of knowledge.

Table 1: Association between the education level and the factors discouraging from buying an electric/hybrid vehicle.

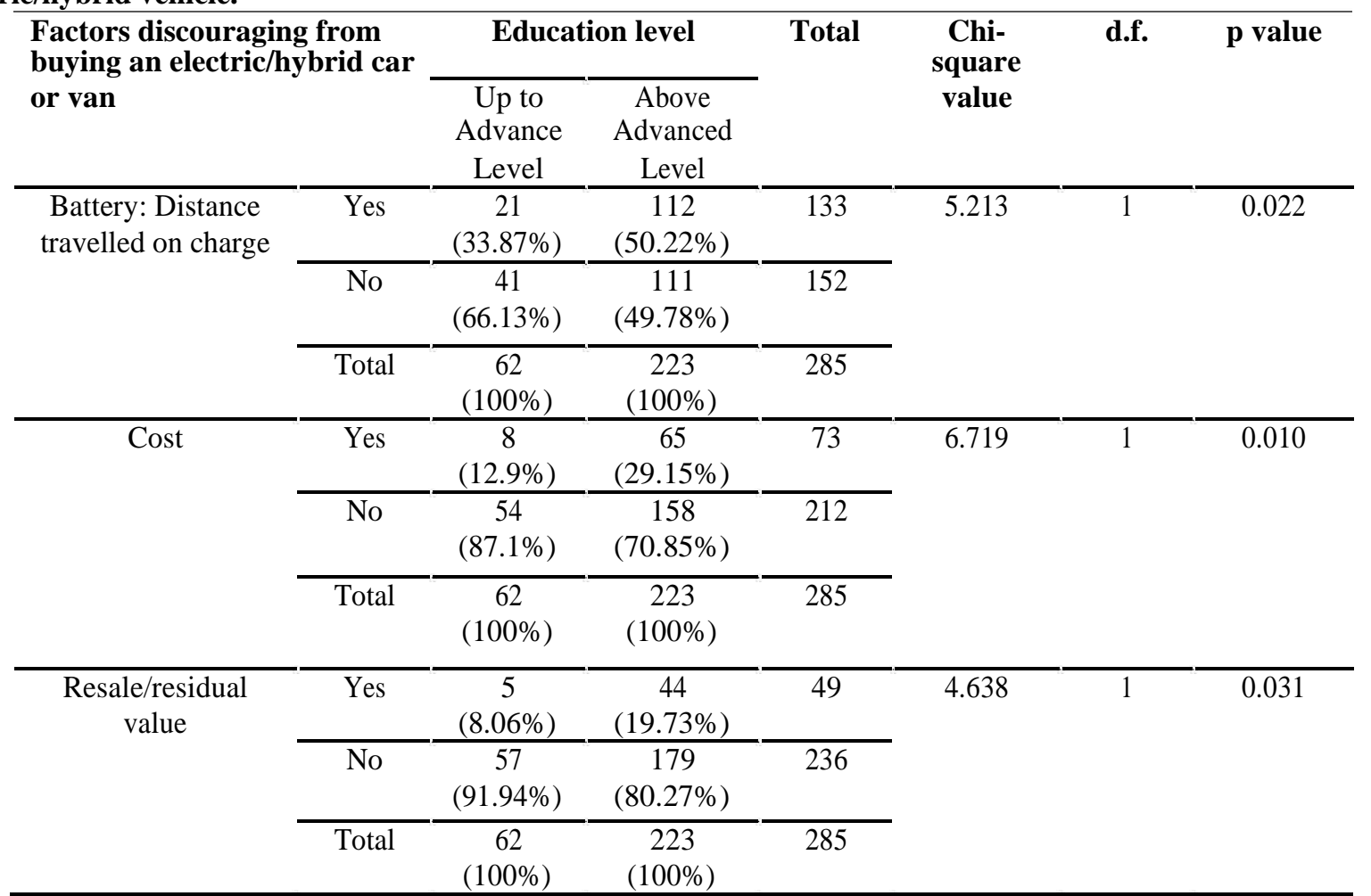

Statistical significance was not noted between the age group and most important feature considered when buying a vehicle: cost, safety, comfort, ecofriendliness. However, significant association was found between the level of education and factors discouraging buying a 'green car': distance travelled on charge, cost and resale (Table 1).

Statistical significance was found between level of knowledge and preference when buying the next vehicle, most $(55 \%)$ of the participants with high level of knowledge were planning to buy a 'green car' as their next vehicle. However, statistical significance was not noted between the level of knowledge and attitudes such as, 'local government should provide incentives to buy eco-friendly cars', 'individual can contribute to reduction in air pollution by buying an eco-friendly car' and 'green cars would replace conventional cars overtime'. 


\section{Discussion}

Bank officers had a satisfactory level of knowledge and awareness about the 'green car' concept. Although, majority of the respondents had ecofriendly attitudes they didn't believe 'green cars' would replace conventional cars over time. Gender, education level and awareness about the 'green car' concept' were significantly associated with mean knowledge score. Bank officers with a higher level of knowledge were found to have more eco-friendly attitudes.

Majority of our participants had a higher level of knowledge and awareness. This is in contrast to the poor awareness level noted in studies conducted on attitudes towards electric cars $[9,10]$. Most had a poor knowledge in recharging section which might be due to the lack of experience with usage of electric cars, since only $15.4 \%$ of the vehicle owners owned a 'green car'. In a similar study on public awareness and attitudes towards electric cars [9] knowledge on recharging was low.

Most of the bank officers believed price of fuel would increase in future and by way of using 'green cars' demand for fossil fuel could be decreased. In contrast, Thiel $\mathrm{C}$ et al [10] states although majority expects price of fuel to increase in future; electric cars were not an identified solution for this problem.

Although eco-friendliness was the feature considered by least number of our respondents $(47.7 \%)$, percentage was not as low as stated by Nair (4.4\%) [3]. According to Chua et al [11] sales of hybrid cars were mainly affected by the buyerse concern about improvement of social standing and personal image rather than buyers ${ }^{\text {ce }}$ care for the environment. Therefore, having pro-environmental attitudes having an incremental effect on 'green car' usage is doubtful.

According to Thiel $\mathrm{C}$ et al [10] geographical difference was noted in the likelihood of buying a green car: In Poland and Spain it was 50\% while in UK and Germany it was less than $30 \%$. If we are to consider what other factors affect this likelihood, one such factor would have been taxes imposed by government at the time of questionnaire administration. Nair [3] states that tax exemption motivates purchasing a 'green car'. In our study as well, majority $(84.5 \%)$ agreed that government should provide incentives to buy 'green cars'. In our group $61.3 \%$ expressed willingness to buy an electric car as their next vehicle.

Age of bank officers was not significantly associated with their level of knowledge. Similarly Nair [3] states: understanding of 'green cars' was the same across all age groups. In contrast, Thiel C et al [10] states that slightly higher level of familiarity in younger people was noticed in comparison to the other age ranges. As in our study, Nair [3]also described no difference in the distribution of knowledge of green cars across all the characteristics of vehicle usage and ownership. Promotional activities carried out currently in our country to improve the sales of 'green cars' might be the reason for improved awareness across all age groups irrespective of vehicle usage and ownership.

Most of the female bank officers considered buying a 'green car' but decided not to, while most of the males were thinking of buying one. If we are to consider the factors influencing this difference it may be because women are more likely not to drive or need a car [12]. Bank officers with a degree were more likely to buy a 'green car' than those without. This may be related to majority of non-degree holders in our study not driving or indicating not needing a car. Similar to our findings Anderson [12] describes those with a degree were more interested in cars being environmentally friendly.

We found a significant association between level of knowledge towards eco-friendly attitudes. Similarly, according to Bradley [13] respondents holding proenvironmental attitudes were having higher level of knowledge about environmental impacts of owning and using vehicles. However, the contrast was described by Nair [3]. We also discovered that level of knowledge was not significantly associated with the belief that green cars would replace conventional cars over time. According to Thiel $\mathrm{C}$ et al [10] although the level of familiarity with electric cars among the respondents was somewhat limited, there were quite optimistic expectations about the number of electric cars sold in the future. This raises the concern on our current status in the journey towards a greener Sri Lanka.

The main limitations in our study were being conducted only in one single institution and involving only a selected profession.

\section{Conclusions}

Majority of the bank officers (68\%) were aware and had a higher knowledge (9.7/10) on the ,green car" concept, although there were some areas of knowledge that required further improvement. In general, the bank officers had eco-friendly attitudes. Most important factors adversely affecting the purchase of a green car were cost, recharging issues and lack of expertise knowledge during a break down. Bank officers who were males, with a degree, 
and aware about the green car concept had a greater knowledge. Age of the bank officers did not affect their decision. Those who owned a vehicle had more environmentally friendly attitudes.

\section{Acknowledgement}

This research was carried out as a requirement of the

Community Stream undergraduate academic programme of the Faculty of Medicine, University of Colombo, Sri Lanka.

\section{References}

1. World Commission on Environment and Development. Our Common Future. Oxford; New York: Oxford University Press 1987:P43.

2. Hagman R, Selvig E. Environmental friendly vehicles: experiences and definitions. Copenhagen: Nordic Council of Ministers 2007.

3. Nair R. Consumer perception and attitudes towards green cars. Journal of Management Development and Research 2012;2(2):52-61

4. Shrestha K. Study of Sri Lanka Vehicle Emissions Testing (VET) Program [summary report] Clean Air Sri Lanka/University of Moratuwa 2012.

5. Union of concerned scientists. State of charge 2014. Available from: http://www.ucsusa.org/cleanvehicles/electric-vehicles/emissionsand-charging-costs-electriccars\#.WFv0trSXef0(accessed 22 December 2016)
6. Muhammad, R, Yahya R, Yusoff HM. Association between Knowledge, Attitude and Practice on Cardiovascular Disease among Women in Kelantan, Malaysia. International Journal of Collaborative Research on Internal Medicine and Public Health 2012;4(8).

7. Wang R, Yang Y, Yuanan L. Knowledge, Attitudes and Practices (KAP) of the Relationship between Air Pollution and Children "s Respiratory Health in Shanghai, China. International journal of environmental research and public health 2015;12(2):1834-1848.

8. Joshi N, Rao PS, Environment Friendly Car: Challenges Ahead in India. Global Journal of Management and Business Research Interdisciplinary 2013;13(4).

9. Northern Ireland Statistics and Research Agency. Public awareness of and attitudes towards electric cars. Belfast: Analysis, Statistics and Research Branch Department for Infrastructure 2012.

10. Thiel C, Alemanno A, Scarcella G, et al. Attitude of European car drivers towards electric vehicles: a survey. JRC report. 2012.

11. Chua WY, Lee A, Sadeque S. Why do people buy hybrid cars?. In Proceedings of Social Marketing Forum, University of Western Australia, Perth, Western Australia 2010.

12. Anderson D. Public attitudes to electric vehicles. Statistical release. Department of Transport 2014.

13. Flamm BJ. Environmental knowledge, environmental attitudes and vehicle ownership and use. UC Berkeley: University of California Transportation Center. 2006. 